\title{
Middle to Late Devonian-Carboniferous collapse basins on the Finnmark Platform and in the southwesternmost Nordkapp basin, SW Barents Sea
}

Jean-Baptiste P. Koehl et al.

Correspondence to: Jean-Baptiste P. Koehl (jean-baptiste.koehl@uit.no)

The copyright of individual parts of the supplement might differ from the CC BY 4.0 License. 

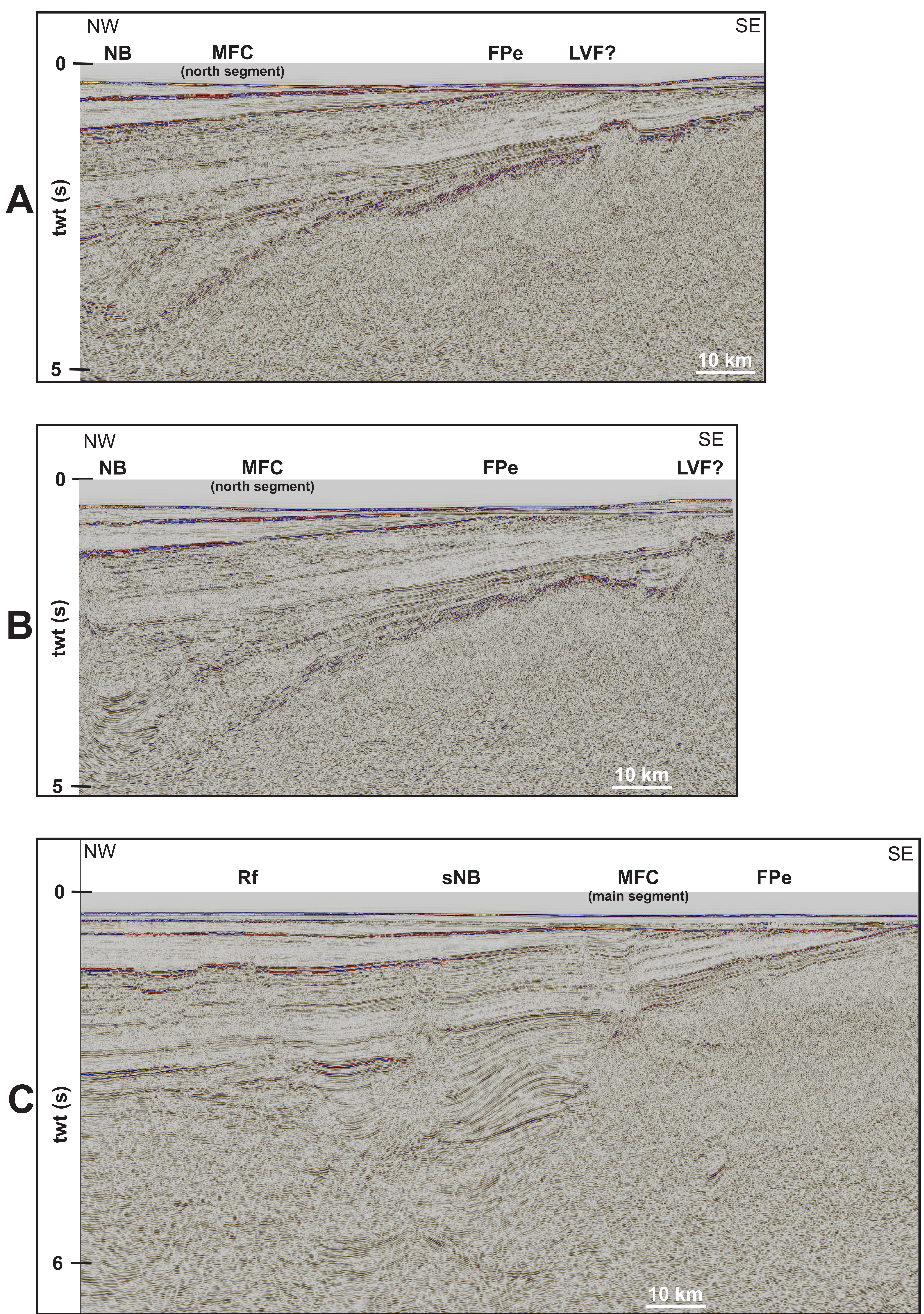


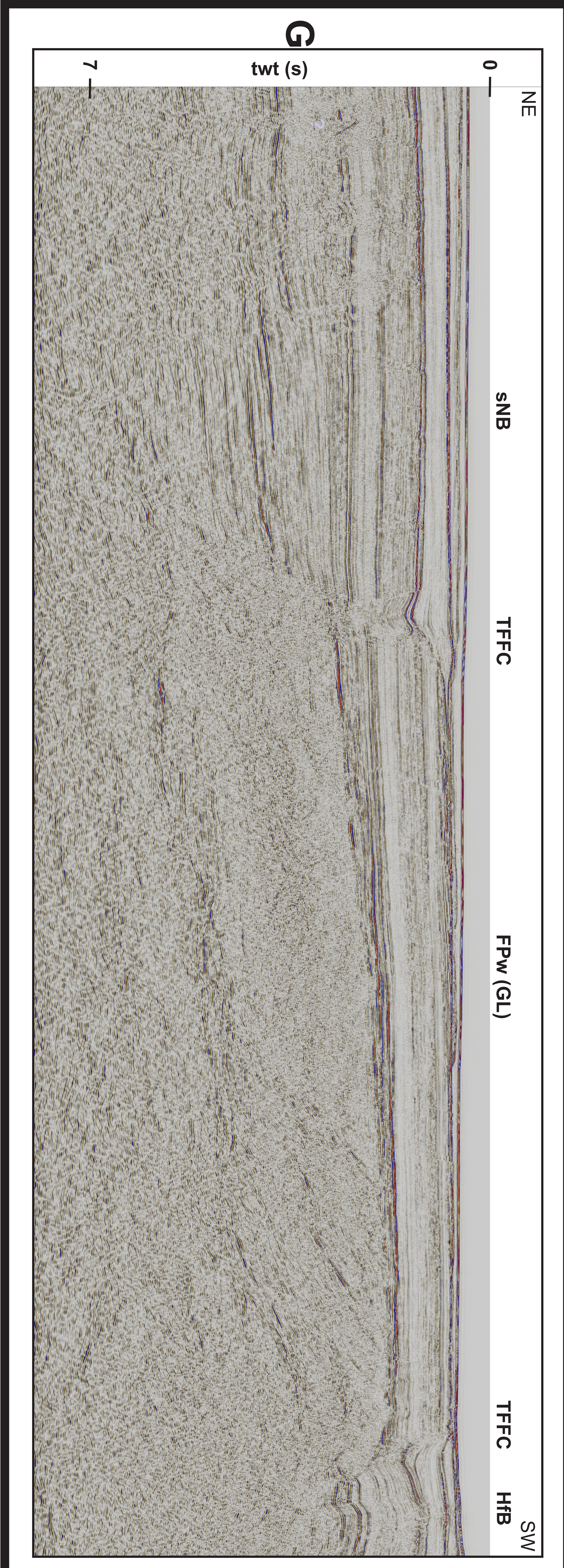

